\title{
Effect of Retainer Materials on Efficiency of Micro- Traction-Drive Utilizing Angular Contact Ball Bearings
}

\author{
Isamu Shiotsu $^{1)^{*}}$, Susumu Matsumoto ${ }^{2)}$, Hiroyuki Sonobe ${ }^{1)}$ and Yasuyoshi Tozaki ${ }^{3)}$ \\ ${ }^{1)}$ Mitsubishi Heavy Industries, Ltd. Machine Tool Division \\ 1, Takamichi, Iwatsuka-cho, Nakamura-ku, Nagoya 453-8515, Japan \\ ${ }^{2)}$ Graduate School of Information, Production and Systems, Waseda University \\ 2-7, Hibikino, Wakamatsu-ku, Kitakyusyu-shi, Fukuoka 808-0135, Japan \\ ${ }^{3)}$ Mitsubishi Heavy Industries, Ltd. Nagasaki Research and Development Center \\ 1-1, Akunoura-machi, Nagasaki-shi, Nagasaki 850-8610, Japan \\ *Corresponding author: Isamu_shiotsu@mhi.co.jp
}

( Manuscript received 29 June 2006; accepted 6 September 2006; published 15 September 2006 )

\begin{abstract}
Micro-Traction-Drive is made by modified angular contact ball bearings. It is developed for the purpose of transmitting high torque with small drive size. Structure of Micro-Traction-Drive is as follows: The traction force is generated by the thrust preload between inner race and outer race. The retainer connected to the output shaft transmits the driving torque. The retainer is made from copper alloy. The test-runs of Micro-Traction-Drive (outer ring diameter 42mm) have been carried out as tandem stage type (reduction ratio 7.3). The test results demonstrate that Micro-Traction-Drive has been successfully operated at 20,000rpm. Furthermore, material of retainer has been examined. Effect of retainer material on efficiency of Micro-Traction-Drive was revealed.
\end{abstract}

Keywords: traction drive, angular contact ball bearing, power transmission, efficiency, planetary type, retainer

\section{Introduction}

For the small size power transmissions, it is necessary to combine an electric motor and a reducer to get adequate performance. Involute profile gears are commonly used for reducers, and very small module gears have to be manufactured for the small size reducer. Therefore, several researches for such small size reducers including the materials and manufacturing methods have been reported. But there are many problems in using small size gears for small reducers. For example, how to keep the precision gear cutting and grinding, difficulty of heat treatment, difficulty of measuring, decreasing torque transmitting ability, and so on.

Considering this situation, authors focused on the "gearless" traction drive. Angular contact ball bearing was chosen for the element of this traction drive, whose retainer was used as output shaft. This traction drive was called "Micro-Traction-Drive", and its reduction ratio was $2.6^{1)}$. Micro-Traction-Drive had better efficiency and larger torque transmitting capacity than the planetary gear drive of the same size of this traction drive. However, Micro-Traction-Drive has a disadvantage that it cannot have large reduction ratio because it uses normal angular contact ball bearings. Since the small motors as power sources are required to run at high speed, reduction ratio larger than 5 will be needed.

In the next step, two-stage type Micro-Traction-Drive has been developed to establish higher reduction ratio and it was driven for confirming power loss or temperature rise. Tests have been conducted in order to evaluate running performance.

In this research, the authors focused on the sliding contact area between rolling elements and retainer that influence the running efficiency. We prepared different material retainers for comparing running performance. Moreover, we compared the conditions of retainer and surface profiles of the contact area after running test.

\section{Design of Micro-Traction-Drive}

\subsection{Structure of Micro-Traction-Drive}

Micro-Traction-Drive is composed of input shaft/ inner ring, outer ring, rolling elements, retainer/output shaft and casing. The rolling elements in pockets of the retainer are preloaded, so that they revolve along the pitch circle. When they revolve, the rolling elements contact with the retainer. The retainer rotates at the same speed as the revolution speed of the rolling elements. Therefore, if the rotation of the retainer is taken out, Micro-Traction-Drive will be a reducer. Figure 1 shows the structure of Micro-Traction-Drive. 


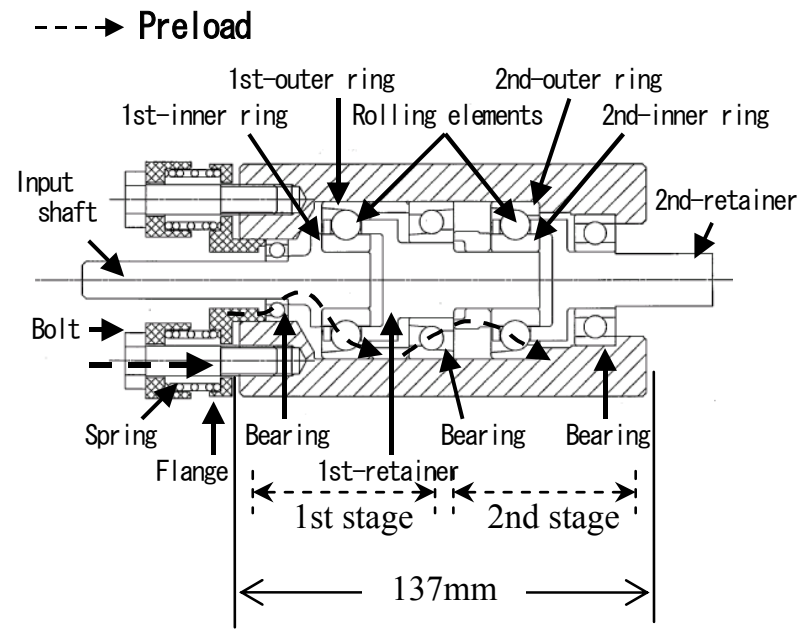

Fig.1 Structure of Micro-Traction-Drive

Micro-Traction-Drive was preloaded by the flange that can move in the axial direction, and this flange was pushed by the springs. The materials of the retainer were CAC302 (high strength brass) which is hard and wear resistant, and CAC502 (Phosphor bronze) which is erosion resistant and easily conform. Both of them were chosen by considering the sliding contact between the retainer and the rolling elements.

\subsection{Dimensions of Micro-Traction-Drive}

Table1 shows the dimensions of Micro-TractionDrive that was used for the tests. For the traction parts, angular contact ball bearings, type 7302 , contact angle $0.262 \mathrm{rad}$ were used.

\subsection{Reduction ratio}

The relationship between the rotational speed of output shaft and input shaft (reduction ratio $i_{s}$ ) is shown as blow.

$$
i_{s}=\frac{N_{\text {in }}}{N_{\text {out }}}=\frac{2}{\left(1-D_{w} \times \cos \alpha / D_{p w}\right)}
$$

$$
\begin{array}{ll}
N_{\text {in }} & : \text { rotational speed of input shaft }[\mathrm{rpm}] \\
N_{\text {out }} & : \text { rotational speed of output shaft }[\mathrm{rpm}]
\end{array}
$$

According to the above formula, the reduction ratio of each stage is 2.7. In this research, a simple structure was employed where two Micro-Traction-Drive of the same size were used. And 1st stage retainer/output shaft was connected to the 2 nd stage input shaft/inner ring directly. So, the reduction ratio was 7.3.

2.4. Relationship between transmitted torque and preload

The traction grease which was used in this test has $0.08 \sim 0.10$ traction coefficient $\mu^{2)}$. The traction coefficient was value when slip ratio was $2 \%$.
Table 1 Dimensions of Micro-Traction-Drive

\begin{tabular}{c|c|c|c}
\hline Inner ring diameter & $d$ & $\mathrm{~mm}$ & 15 \\
\hline Outer ring diameter & $D$ & $\mathrm{~mm}$ & 42 \\
\hline Outer ring Width & $L$ & $\mathrm{~mm}$ & 13 \\
\hline Contact angle & $\alpha$ & $\mathrm{rad}$ & 0.262 \\
\hline Rolling element P.C.D & $D_{p w}$ & $\mathrm{~mm}$ & 29.5 \\
\hline Rolling element diameter & $D_{w}$ & $\mathrm{~mm}$ & 7.938 \\
\hline Number of rolling elements & $z$ & - & 3 \\
\hline Reduction ratio (Single) & $i_{s}$ & - & 2.7 \\
\hline Reduction ratio (Tandem) & $i_{t}$ & - & 7.3 \\
\hline
\end{tabular}

Preload $F a$ was calculated by the following equation. For example, an output torque $T$ of $0.16 \mathrm{Nm}$ and a traction coefficient $\mu$ of 0.08 gives $F a$ of $23 \mathrm{~N}$.

$$
\begin{aligned}
& F a= \frac{T \times \sin \alpha}{\mu \times D_{p w}} \times 1000 \\
& \mu \quad: \quad \text { traction coefficient }(0.08 \sim 0.10)^{2)}
\end{aligned}
$$

\section{Test}

\subsection{Test facility}

Test facilities (Measuring devices, Driving motor, Brake) layout is shown in Fig.2. The rotational speed of input and the output shaft was measured by the optical pulse counter. The input torque was converted by using electric current value of the motor. The output torque was measured by torque meter. The temperature of MicroTraction-Drive and support bearings were measured by the thermocouples. The DC motor (Ratings capacity 200W) was used for the driving motor. The electromagnet brake (Maximum torque $0.25 \mathrm{Nm}$ ) was used for the brake. The torque meter capacity was $0.5 \mathrm{Nm}$.

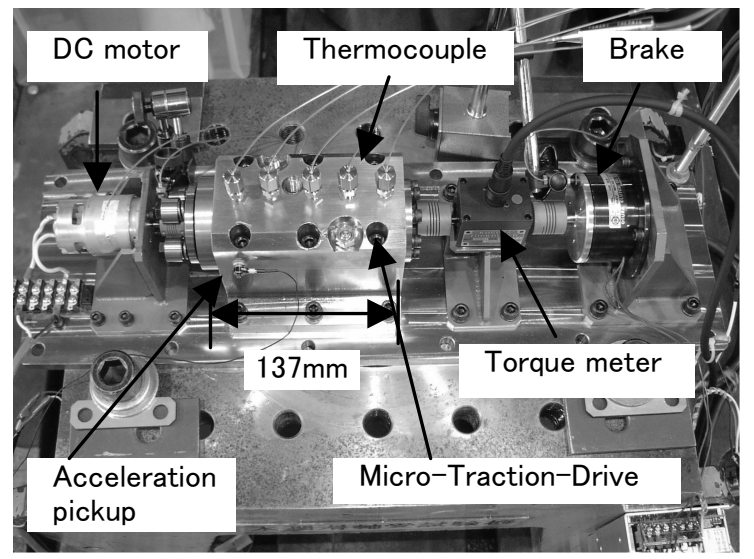

Fig.2 Test apparatus of Micro-Traction-Drive 


\subsection{Test conditions}

Test conditions are shown in Table 2. The range of the rotational speed of the input shaft was set to 0 to $20,000 \mathrm{rpm}$. The rotational speed of the input shaft was raised at a constant acceleration for 2 minutes. The output shaft torque was set to $0.08 \mathrm{Nm}, 0.16 \mathrm{Nm}$ and $0.24 \mathrm{Nm}$.

\section{Results of test}

\subsection{Efficiency}

Measurement results of running efficiency are shown in Fig.3. The running efficiency using retainer made of high strength brass was about $79 \%$ at maximum. The running efficiency using retainer made of phosphor bronze was about $83 \%$ at maximum.

Table 2 Characteristic test conditions

\begin{tabular}{c|c}
\hline $\begin{array}{c}\text { Rotational speed of } \\
\text { input shaft }\end{array}$ & $0 \sim 20,000 \mathrm{rpm}$ \\
\hline Output shaft torque & $0.08,0.16,0.24 \mathrm{Nm}$ \\
\hline Material of retainer & $\begin{array}{c}\text { CAC502 (Phosphor bronze) } \\
\text { CAC302 (High strength brass) }\end{array}$ \\
\hline Temperature & $\begin{array}{c}\text { Room temperature } \\
\text { of about } 20^{\circ} \mathrm{C}\end{array}$ \\
\hline Lubricant & $\begin{array}{c}\text { Base oil : Synthetic oil } \\
\text { Viscosity : 32mm } / \mathrm{s} @ 40^{\circ} \mathrm{C} \\
\text { Consistency : 400 430 }\end{array}$ \\
\hline
\end{tabular}

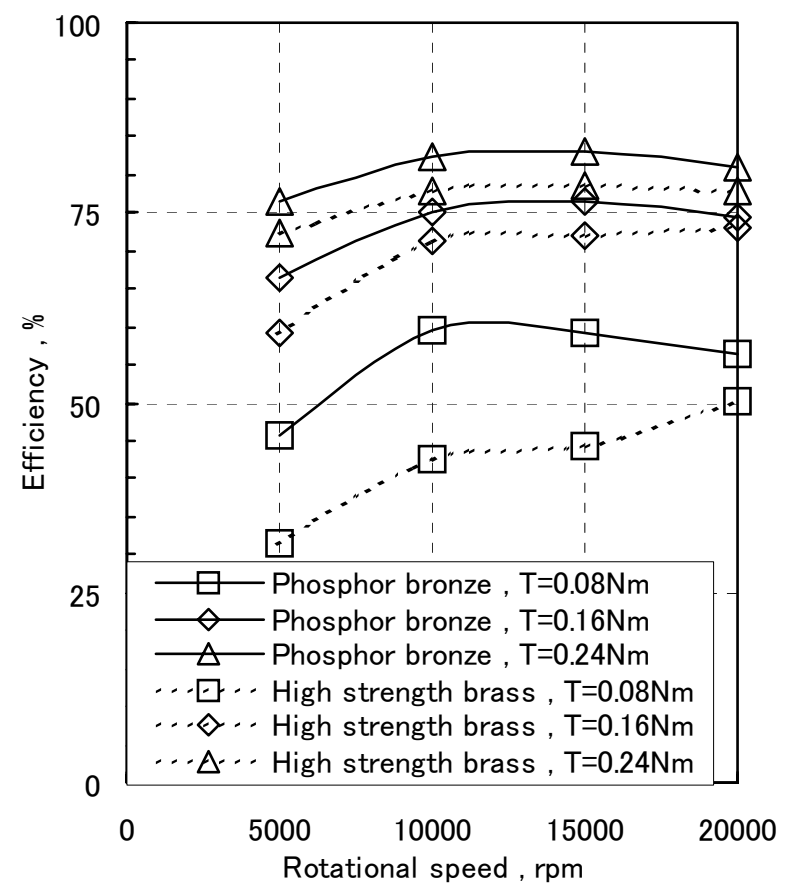

Fig.3 Rotational speed of the input shaft vs. Efficiency
At the output shaft torque of $0.08 \mathrm{Nm}$, the running efficiency using retainer made of phosphor bronze was $15 \%$ higher than using retainer made of high strength brass.

\subsection{Condition of retainer contact surface}

Appearances of pocket of the retainers are shown in Fig.4 and 5. Both retainers did not have excessive wear and seize. This suggests that the contact areas were properly lubricated with the grease.

Measurement results of the surface profile are shown in Fig.6 to 9. The retainer made of phosphor bronze was worn so as to conform to the rolling element near the center (Fig.6, 7). The retainer made of high strength brass did not exhibit such trace of wear for conformation (Fig.8, 9).

The contact surface of the retainer made of phosphor bronze had run in with the rolling elements. The calculation results using the surface profiles of film parameter $\Lambda$ are shown in Fig.10. At the rotational speed of the input shaft of $5000 \mathrm{rpm}$, film parameter $\Lambda$ of 2nd-retainer after the test was about 3.
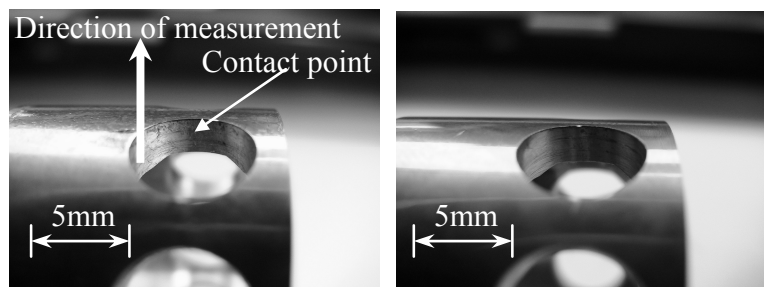

Fig.4 Appearance of the retainer (phosphor bronze) Left : 1st stage, Right : 2nd stage
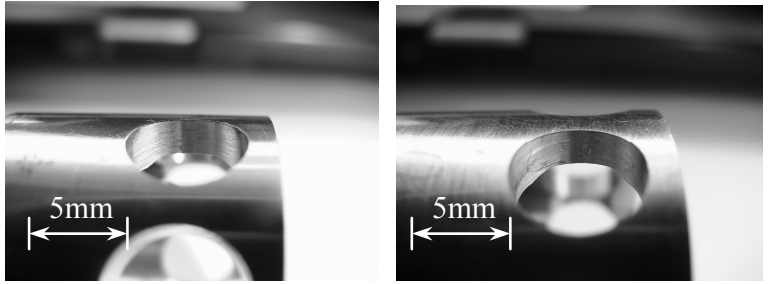

Fig.5 Appearance of the retainer (high strength brass) Left : 1st stage, Right : 2nd stage

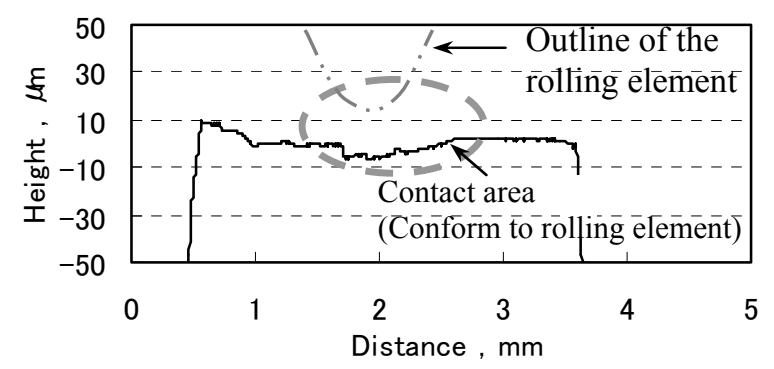

Fig.6 Profile of pocket of the retainer (Phosphor bronze, 1st stage) 


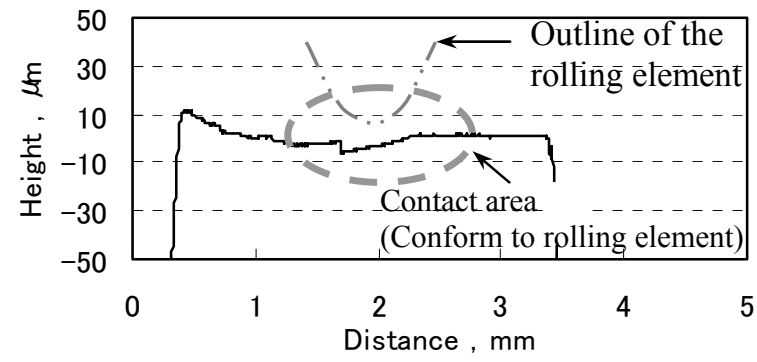

Fig.7 Profile of pocket of the retainer (Phosphor bronze, 2nd stage)

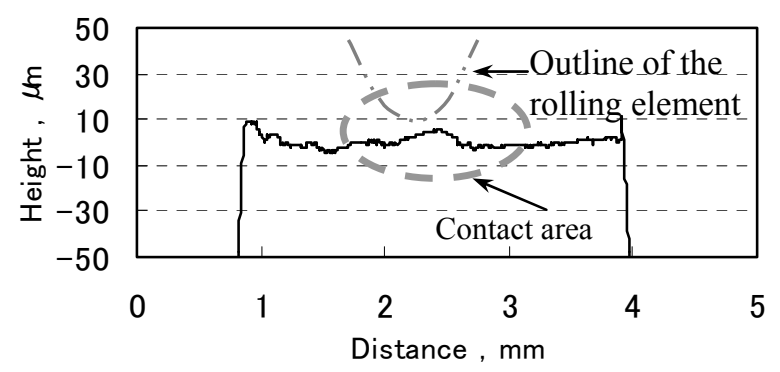

Fig.8 Profile of pocket of the retainer (High strength brass, 1st stage)

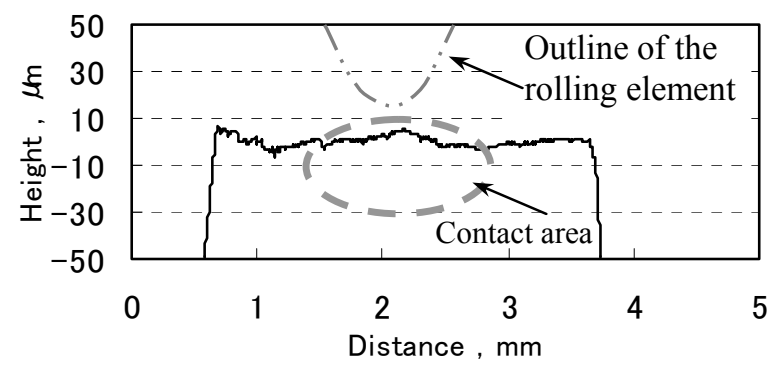

Fig.9 Profile of pocket of the retainer (High strength brass , 2nd stage)

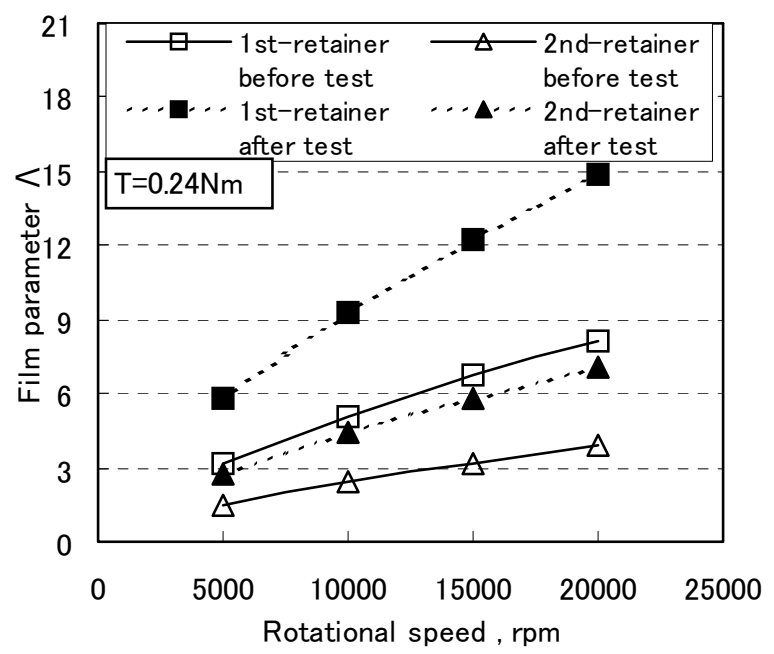

Fig.10 Film parameter between retainer made of phosphor bronze and rolling element
After the test, the lubricated condition of the contact surface of 2nd-retainer was hydrodynamic lubrication, and the friction loss of the contact surface decreased.

Therefore, the favorable running-in must have led to the high efficiency with the retainer made of phosphor bronze as compared with the retainer made of the high strength brass.

\section{Conclusions}

The efficiencies of Micro-Traction-Drive with two different materials for the retainer were compared, and the worn surfaces of the retainers were studied.

From the results of the tests, the following conclusions were obtained.

- The running efficiency using retainer made of high strength brass is about $79 \%$ at maximum and using retainer made of phosphor bronze is about $83 \%$ at maximum. These values are sufficiently large for a gear head of small motors, because the running efficiency of ordinary two stage type planetary gear head is in the range between 70 and $80 \%{ }^{3}$.

- The contact surface of the retainer made of phosphor bronze was slightly worn in the initial running-in wear to conform to the rolling elements. The lubricated condition of the contact surface became hydrodynamic lubrication, and the friction loss of the contact surface decreased. This running-in could provide the higher running efficiency with the retainer made of phosphor bronze as compared that the retainer made of high strength brass.

\section{References}

[1] Tozaki, T., Umeda, A., Sonobe, H., Matsumoto, S., Yoshimi, T. and Shiotsu, I., "Performance evaluation of innovation Micro-Traction-Drive utilized angular contact bearing," ASME J. Tribology, 128, 2, 2006, 262-266.

[2] Yamazaki, T., "Traction drive and lubricant," Nikkan Kogyo Shimbun, Mechanical design, 24, 11, 1980, 117-121.

[3] "Maxon motor 2004/05," Maxon Japan, 2004, $187-224$. 